\title{
The Role of Managers as Agents in Successful Service Innovations: Evidence from India
}

\author{
Shiv S. Tripathi
}

\author{
"One person should not give orders to another person, but both") \\ should agree to take their orders from the situation. If orders \\ are simply part of the situation, the question of someone \\ giving and someone receiving does not come up.
}

Mary Parker Follett (1868-1933)

Management theorist and consultant

\begin{abstract}
The article is based on a three-year study of 70 business executives belonging to 20 large organizations operating in India to identify the kind of interventions used by agents (managers) to make service innovations successful. For the purpose of analysis, the subject organizations were classified into highly successful, successful, and unsuccessful organizations on the basis of their growth rate, and their practices were analyzed to identify the role of agents in those processes or related decisions. The article also compares the practices followed by organizations based in India with global organizations operating in India to understand the contextual issues of service innovations.
\end{abstract}

\section{Introduction}

According to Gallouj (2002), services have three distinct features: i) they are processes, ii) they are interactive, and iii) there can be extremely diverse. This complex nature of services sets them apart from products (i.e., goods), whose development is relatively linear and independent. When a service-based organization chooses the path of innovation, it needs to be careful, because the development of successful service innovations requires more careful thought than the development of products. A company can offer an innovative service only when there is a management resolve and the service has a high probability of success in the market (Van de Ven, 1986). The reason is that service innovations are often a result of the demand of market or the clients (Barras, 1986; Pavitt, 1984), co-production (den Hertog, 2000), or close co-operation of the supplier and the client (Tether \& Hipp, 2002). Therefore, unlike product innovations, whose acceptance or rejection by the market or the clients is visible almost immediately after the launch, services take a relatively longer time to gain acceptance. Industry-wise, there is also a marked distinction between manufacturing/product-based firms and service-based firms: the latter focus more on organizational innovations as compared to the product or process innovations of the former (Chamberlin et al., 2010). Thus, service innovations have organization-wide effects, whereas product innovations might affect only one line of business or product.

Another difficulty is that the immediate advantage of a service innovation may not be as objectively visible as a product; hence, service-innovation ideas may face increased scrutiny prior to implementation (de Jong et al., 2003). However, once a service innovation is implemented, and the feedback is positive, gaining commercial advantage can be relatively easier.

Thus, if a service-based organization wants to innovate, the agents (managers) have an important role to play in seeing that the service innovation overcomes every hurdle, because it is an organization wide effort that makes a service innovation successful. However, a key question remains as to whether the support provided by these agents really does make service innovations successful or whether these agents knowingly or unknowingly act as an impediment to successful service innovations. 


\section{The Role of Managers as Agents in Successful Service Innovations}

\section{Shiv S. Tripathi}

To help answer this question we look to agency theory. A typical agency relationship is the one where one party (i.e., the principal) delegates work to another (i.e., the agent) who performs that work (Jensen \& Meckling, 1976). Agency theory is concerned with solving two problems that might occur in agency relationships. The first problem occurs when the desires and goals of the principal and agent are in conflict with each other and it is difficult for the principal to verify what the agent is actually doing. The second problem occurs when the principals and agents have different attitudes towards risk. The present article focuses on the second issue, where the daily demands of their work cause the agents (managers) to become risk averse and thus curb the real spirit and potential of innovation present in the organization, which often brings them into conflict with the principal (Eisenhardt, 1989). Due to this risk aversion, an agent might apply their discretion in matters related to inputs, processes, and outputs of innovation and will not involve or pay attention to the frontline coworkers (Edgett \& Parkinson, 1994, Easingwood, 1986), which might give birth to a "routines" that curb the development of a radically innovative service.

Thus, large organizations are faced with a dilemma as to whether to support innovations or focus on the sustainability of the organization. The solution lies in combining both efforts. The first part of the dilemma is the agency conflict: agents at all levels may not be ready to take risks that the principals might want them to take. The second part of the dilemma is the difficulty in making the organization sustainable, which is a challenge faced not only by startups but also large and established organizations, who may struggle to achieve for sustainable growth (McGrath, 2013). The present research is limited to large organizations only and explores the process of service innovations in large private sector organizations operating in India, including global organizations operating in India.

This article also examines the leadership view of an organization, which suggests that, even if an organization has the requisite resources and dynamic capabilities, it is the leadership that steers the innovative new service towards success (Chandy \& Tellis, 2000; Si \& Wei, 2012). It has been reaffirmed by researchers that visionary leadership is a necessary ingredient for innovation (Anderson \& West, 1998; Thamhain, 2003; Tidd \& Bessant, 2009) and therefore, the amount of time spent by senior executives on activities related to innovation is also important. Therefore, this article critically examines the role of executives as agents in successful service innovations.

\section{Research Methodology}

The current study is based on 70 in-depth interviews, lasting between 40 minutes and 1 hour and 45 minutes, with experienced executives from 20 organizations either based in India (8 organizations) or operating in India (12 global organizations). Each of these organizations were large (cf. OECD, 2005); each had a turnover of at least $\$ 200$ million USD and was listed in one or more of the following stock exchanges: New York Stock Exchange, London Stock Exchange, Nasdaq, Bombay Stock Exchange, or the National Stock Exchange (of India).

Only service innovations developed by these subject organizations in the previous two years were considered. These service innovations included incremental or radical innovations but excluded routine process improvements. The idea was to select those service innovations that had a positive impact on revenue growth of the organization.

The organizations were categorized into highly successful, successful, and unsuccessful organizations based on three years of compounded annual growth rate (CAGR) of their net profit after tax. Organizations having a growth rate over $20 \%$ were classified as highly successful, those with growth rates between zero and $20 \%$ were classified as successful, and those having a negative growth rate were classified as unsuccessful.

Out of 22 items included in the discussion guide for the interviews (Tripathi et al., 2013), 19 analytical items were identified as themes that were discussed in detail with the respondents. The other three items were dropped because they were direct questions. In the following section, the practices followed by each category of organization are listed. A parallel comparison between organizations based in India and their global counterparts operating in India is also made, and discussion of the overall role played by the agents in these organizations is provided. The responses against each type of organization are the actual direct responses of the respondents analyzed through grounded theory methodology following Strauss and Corbin (1998).

\section{Summary of Key Findings}

For each of the 19 themes, this section summarizes the typical response from the interview subjects based on the success level of their organization. Also, for each theme, the role of agents in organizations based in India is compared against global organizations based in India. 


\section{The Role of Managers as Agents in Successful Service Innovations}

\section{Shiv S. Tripathi}

\section{Theme 1: Number of innovators in the organization}

- Highly successful organizations: innovators include top management and the majority of managers, but innovation is encouraged throughout the organization

- Successful organizations: top 5-10\% of employees; primarily, senior management is the driver; a few other managers also drive innovation

- Unsuccessful organizations: only the top management drives innovation; others are not encouraged

- Role of agents: only the top management controls the innovation front; employees down the line are not empowered to innovate. In contrast to organizations based in India, the process is more democratized with their global counterparts, where it is not limited to the top management, and employees down the line are encouraged to innovate in services.

\section{Theme 2: Incentives for innovation}

- Highly successful organizations: primarily non-monetary incentives, such as awards, recognition, job advancements in India or abroad, or implementation of ideas

- Successful organizations: no incentives unless there are patents; primarily rewards and recognition for patents

- Unsuccessful organizations: monetary incentives such as one-time rewards, gifts (e.g., iPads), or a lump sum . The belief is that monetary incentive is better because, when there is a lot of scope for innovation, the organization cannot recognize everyone.

- Role of agents: for companies based in India, the rewards and recognition systems are typically driven by agents and are often discretionary (and biased). The opposite is true with most of their global counterparts who rely on an open reward system with minimum intervention, often as part of a process of innovation that includes a reward system.

\section{Theme 3: Frequency of change of mission statement}

- Highly successful organizations: as per the demand of the market or business environment; to stay ahead in the market; as per changing market dynamics

- Successful organizations: changed rarely or not changed unless there is a restructuring
- Unsuccessful organizations: changed rarely or not changed unless there is a restructuring or crisis

- Role of agents: the agents in Indian organizations are not bothered about the internal communication of the change in mission statement because they do not feel it is important. In contrast, their global counterparts are relatively active in communicating any change in the mission statements to employees down the line, because they believe it enables better control and synchronization across all subsidiaries, and maintaining good communication and transparency.

\section{Theme 4: Time to market}

- Highly successful organizations: instantaneous to maximum of six months in the case of small improvements; in case of a major capital expenditure project, it may take up to one year

- Successful organizations: the majority of successful organizations require two to six months for small ideas/projects to reach the market; for large ones, up to one year

- Unsuccessful organizations: for small improvements the time to market is two to six months; for large ones, it takes two to five years

- Role of agents: if the idea provides a promising business opportunity or competitive advantage, agents in both types of organization take an active interest so that the service is launched in the market. Therefore, both the India-based organizations and their global counterparts are similar in this regard.

\section{Theme 5: Number of ideas pursued by the company in a year}

- Highly successful organizations: 10 to 15 ideas per year

- Successful organizations: two to five ideas in a year; the limitation is the capacity to execute, not the lack of ideas

- Unsuccessful organizations: none, one, or two ideas; respondents had no idea what was happening in other departments; execution is a problem

- Role of agents: distinctively, the agents in Indian organizations promote two to five ideas per year, out of which they expect one or two ideas to succeed. Their global counterparts allow all potential ideas to pass 


\section{The Role of Managers as Agents in Successful Service Innovations}

\section{Shiv S. Tripathi}

through the stage gates of innovation. However, agents in Indian organizations try to dictate the selection of final ideas, which results in execution problems at a later stage.

\section{Theme 6: Time required in funding innovation}

- Highly successful organizations: funding is immediate or within six months; whatever time taken (if any) is for the feasibility study

- Successful organizations: two to six months in most cases where the scale of implementation is small and one to three years where the scale of implementation is large

- Unsuccessful organizations: if the service is successful, there is no problem: adequate funds are available. However, the time depends on the amount of funds required and, at times, it is expedited if the person is a veteran in the company. Thus, employees with less experience find it difficult to negotiate for funds even if their ideas are commercially the best.

- Role of agents: although agents in both types of organizations show equal eagerness to fund potential innovations, in Indian organizations, the vision of agents is sometimes coloured by the experience and stature of the person floating the idea, and tend to neglect the ideas of a relatively new employee, at times even at the cost of merit.

Theme 7: Number of services the company is planning to launch in the next year

- Highly successful organizations: 20 to 30 service ideas are floated, but ultimately, only one or two merit a feasibility study

- Successful organizations: 20 to 100 ideas are floated; 20 to 100 merit a feasibility study

- Unsuccessful organizations: 10 to 15 ideas are floated; one merits a feasibility study

- Role of agents: both Indian and global organizations promote the ideation of new services; however, when comes to finalizing a new service for the client, the Indian organizations are at times biased towards the past successes and are not willing to accept radical departures from the past. Therefore, the agents in Indian organizations start looking at the background of an innovator as compared to the merit of an idea.

\section{Theme 8: Number of intrapreneurs}

- Highly successful organizations: at most, 5\% of employees might have directly contributed; otherwise they all contribute because it is presumed to be a part of their job.

- Successful organizations: around 10 people at the top (i.e., a specific number that can be counted), but others are not empowered to be intrapreneurs

- Unsuccessful organizations: maximum 1-3\% people at the top

- Role of agents: In Indian organizations, intrapreneurs by and large belong to the top management only. In global organizations, an employee even at a junior level has the opportunity to spearhead the service innovation if their idea is accepted.

\section{Theme 9: Number of employees becoming entrepren- eurs after leaving the company}

- Highly successful organizations: one to ten employees (i.e., a specific number that can be counted)

- Successful organizations: very few or none; most employees who leave the company join another company

- Unsuccessful organizations: very few people leave the organization to become entrepreneurs, they leave to join a better company

- Role of agents: due to a limited scope of corporate entrepreneurship owing to agents and at times due to the nature of business, a number of employees leave Indian organizations to start their own business or to take up greater responsibilities in other organizations. However, their global counterparts do not typically leave organizations to start a new business; rather they switch organizations to take up greater responsibilities elsewhere.

\section{Theme 10: Percentage of people trained in innovation}

- Highly successful organizations: around 30-40\% employees are trained in innovation

- Successful organizations: around 10-30\%; for most of employees, there is no training on innovation per se

- Unsuccessful organizations: 1 to $2 \%$ of top management people are trained in innovation. Others are 


\section{The Role of Managers as Agents in Successful Service Innovations}

\section{Shiv S. Tripathi}

provided with routine training on services because they are not empowered to innovate.

- Role of agents: in Indian organizations, innovation training is typically initiated and given only to the agents (especially the top management); others are provided with the routine training only. However, their global counterparts provide training in innovation not only to the agents but also to key employees, irrespective of their level in the management hierarchy.

\section{Theme 11: Number of people agreeing that there is a fo-} cus on strategic innovation

- Highly successful organizations: around 75\% of employees would agree, but employees are unhappy when they lose out to competition

- Successful organizations: 10-30\%

- Unsuccessful organizations: $60-80 \%$

- Role of agents: here, the agents play a positive role in motivating the actors sufficiently so that they believe that the organization is innovating strategically innovations even if it is not actually able to do so. Personal interaction plays a major role in the Indian organizations, whereas in the global counterparts, all service innovations are promoted internally as well as externally so that everybody comes to know about a particular service.

Theme 12: Existence of a process to generate new business ideas within the company or outside the company

- Highly successful organizations: in a majority of cases, processes for both directions exist

- Successful organizations: idea generation is primarily "in-house"; there is an absence of process in some cases

- Unsuccessful organizations: idea generation is primarily "in-house"; implementation is a problem.

- Role of agents: the agents in this case act as gatekeepers who may "kill" the idea at one stage or another if they do not believe in it. All organizations based in India lacked a formal process to generate new business ideas either in-house or from outside the organization. Their global counterparts operating in India had processes in place and thus avoided the interference of agents.

\section{Theme 13: Availability of funds for innovation}

- Highly successful organizations: plenty of funds are available, but there is a lack of good ideas

- Successful organizations: sufficient funds are available; outside collaboration is not required for financing; for high-risk projects, collaboration diversifies the risk

- Unsuccessful organizations: enough funds are available, but formal processes for innovation and fund allocation are lacking

- Role of agents: the agents controlled the sources and allocation of funds, and at times promoted mediocrity by allocating the funds to a favourite and not to the person having the best service innovation. In the global organizations, although the agents controlled the allocation of funds, they could not be biased because there were processes in place where only the winning ideas for service innovation would receive funding.

\section{Theme 14: Responsiveness of top management}

- Highly successful organizations: top management takes responsibility and is cooperative; it is a part of company culture

- Successful organizations: in most cases, top management takes responsibility or provide support

- Unsuccessful organizations: in many cases, top management will not take responsibility unless they are liable to take the blame for failure; there is also difficulty in implementing innovations

- Role of agents: in the majority of the above themes, there were thorough interventions by agents in Indian organizations; as a consequence, they took the responsibility for failures of innovative services provided unless there was an opportunity to place blame on others. In their global counterparts, because independence was given to the person whose idea of service innovation was implemented, the person heading the project directly held the responsibility for its success or failure, and the agents had no intervening role. 


\section{The Role of Managers as Agents in Successful Service Innovations}

\section{Shiv S. Tripathi}

Theme 15: To launch a new service or revive an existing one

- Highly successful organizations: consider launching a new service almost every time

- Successful organizations: launch and revival in the ratio of 60:40; would launch new services if able to do so

- Unsuccessful organizations: launch new services in most cases

- Role of agents: the agents in almost all Indian organizations promoted the revival of existing services as the first option and launching new services as the second; they had limited willingness to take risks. Even when there was a requirement to launch new products, the agents used it as a last resort and therefore "killed" the launch of a new service at the right time in the market. Their global counterparts took calculated risks, although they preferred to launch new service as compared to reviving the old services. However, exceptions to these typical scenarios were found in both types of organizations.

\section{Theme 16: The number of services being deliberately developed since last year}

- Highly successful organizations: on their own, one to two services; as per the client's demand - 15 to 20; patents were being filed as required by the companies

- Successful organizations: in a majority of cases, two to five; patents were being filed as required by the companies

- Unsuccessful organizations: deliberately, one to two services; activities in the rest of the organization were not known

- Role of agents: the agents of Indian organizations promoted the development of one to two services only, whereas their global counterparts promoted substantially more due to the fact that the new service innovations were directive-driven in the Indian organizations as compared to proactive developments by the global organizations.

Theme 17: Perception of employees about their company innovating to stay ahead in the market

- Highly successful organizations: positive; employees perceive that their organization is better able to read industry trends than others

- Successful organizations: in a majority of cases, the perception is that their organization is innovating or at least attempting to innovate

- Unsuccessful organizations: the perception is that their organization innovates as the market dynamics requires and to stay visible in the market

- Role of agents: the agents of both types of organizations were able to create an environment in which the employees thought that their company innovates to stay ahead in the market. This perception was a result of mentoring provided by the agents in Indian organizations and empowerment provided by the agents in the global organizations.

\section{Theme 18: On innovating as required by the client or on its own}

- Highly successful organizations: in a majority of cases, both drivers of innovation exist

- Successful organizations: both drivers of innovation exist, but in a majority of cases, it depends on market need or when the clients demand particular solutions.

- Unsuccessful organizations: mostly as required by the market

- Role of agents: the agents of most of the Indian organizations promoted the maintenance of status quo and were reluctant to support service innovations on their own unless the technology itself evolved or it was demanded by the client. In contrast, their global counterparts were more involved in supporting the development of service innovations proactively so that they can offer them to their clients before any competing organization does.

\section{Theme 19: The success rate of innovative services launched by the company}

- Highly successful organizations: $30-50 \%$ in most cases

- Successful organizations: $30-40 \%$ in most cases

- Unsuccessful organizations: around 20\%

- Role of agents: the success rate of service innovations in Indian organizations was similar to their global counterparts due to the quantity of new ideas for ser- 


\section{The Role of Managers as Agents in Successful Service Innovations}

\section{Shiv S. Tripathi}

vice innovations supported by the agents. Although the Indian organizations followed fewer ideas and experienced fewer failures, the global organizations followed more ideas and achieved more successes.

\section{Discussion and Conclusion}

The findings suggest that, in Indian organizations, there is a substantial intervention by agents across most of the themes as compared to their global counterparts operating in India. In most cases, the intervention of agents is negative: for example, innovators are limited to a number of agents; awards/rewards for innovation are at the discretion of agents; agents do not feel the need to convey major changes in the direction of company to people down the line; there is a lack of a formal process for fund allocation to innovation projects; agents avoid accepting fresh ideas by relatively inexperienced people; they keep intrapreneurship opportunities to themselves; a formal process for idea generation is absent, giving agents discretionary powers; there is virtually no innovation training except to agents at a certain level; agents are risk averse in terms of launching new services; and there is a lack of interest in proactive service innovation among agents. Since there is a high degree of negative intervention of agents in the service innovation process, it becomes supervisor-driven and not self-driven, and that is why organizations in India tend to follow a kind of "directed innovation". In certain cases, where the agent (or manager) provides mentorship personally to staff at lower levels, it is a positive intervention provided they empower those employees to take decisions on their own.

To understand the cause of these often negative interventions of agents one needs to first understand that India follows a management system that is neither too individualistic, like the United States, nor it is purely collectivist, like Japan; rather, it is somewhere in between. This "in between" position gives substantial discretionary powers to the agents in Indian organizations who generally have an option to go towards any of these two extremes at their discretion. Second, because most of the sectors in the Indian economy have yet not become hypercompetitive as there is still a scope for growth, such negative interventions of agents might affect the innovations but it does not affect the growth or sustainability of the organizations, which can still flourish. However, such interventions will become a deterrent to growth the moment a particular sector becomes completely saturated. In that situation, innovation would be the only route to survival. Yet, in order to create a culture of innovation, there should be processes in place to avoid any bias; this culture would enable an organization to bring out the true potential of its employees.

However, if we compare Indian organizations with their global counterparts operating in India, the element of discretion of agents at various stages of service innovation is limited or absent. The first reason is that most of the organizations whose employees were interviewed had well-defined processes, for example, for idea generation or allocation of funds, and thus minimized the role of agents in positively or negatively affecting the process. Second, the parent organizations of these companies reside in countries where the local market was saturated, and that is why they saw the solution to growth through innovation in a structured manner. There is a very little discretion available to the agents, and their approach is more objective. Third, the large size of these global organizations makes them more likely to have systems and processes in place and reduces the influence of local contextual factors in different parts of the world.

Based on the above discussion there, the following recommendations are provided for organizations wishing to pursue service innovations in India. Although they are targeted at Indian companies, they may also be relevant to global organizations with operations in India:

1. Have clear processes for innovation: To minimize the discretion of agents and ensure that there is objective assessment, companies should try to have clear systems and processes for the various components and phases of innovation including incentives, idea generation idea evaluation, and funding. Let the system of processes take over the task of producing successful service innovations and not the agents.

\section{Empower employees and support them in risk-tak-} ing: The agents can mentor the people down the line yet provide them independence and empowerment so that they not only believe that their organization is innovative but also they can see it in action. In this process of empowerment, the employees should not feel alienated.

3. Get off the fail-safe track: Indian companies can break free from the fail-safe types of services or the fail-safe image of the agents by inviting fresh ideas and giving them an honest evaluation. In some cases, the same fail-safe idea or service may be selected. 


\title{
The Role of Managers as Agents in Successful Service Innovations
}

\author{
Shiv S. Tripathi
}

But, the difference would be that it would be a deliberate and open selection based purely on merit within a culture where everyone feels involved in the process.

Due to the complex nature of services, service innovation require clear cut processes, close co-operation, and interaction between various functional areas and stakeholders so that they have a feeling of ownership in the organization. Agents should always keep the communication channels open to all levels to encourage transparency and feedback in the system, because even a seemingly small issue may curb the success of a service. Agents can always provide positive interventions in the process of service innovations by being approachable; welcoming ideas from any level in the organization; creating and supporting the system to take care of all processes; and acting as a mentor and not as an actor in the process of building successful service innovations.

\section{References}

Anderson, N., \& West, M. A. 1998. Measuring Climate for Work Group Innovation: Development and Validation of Team Climate Inventory. Journal of Organizational Behavior, 19: 235-258. http://dx.doi.org/10.1002/(SICI) 1099-1379(199805)19:3<235::AIDJOB837>3.0.CO;2-C

Barras, R. 1986. Towards a Theory on Innovations in Services. Research Policy, 15(4): 161-173.

http://dx.doi.org/10.1016/0048-7333(86)90012-0

Chamberlin, T., Doutriaux, J., \& Hector, J. 2010. Business Success Factors and Innovation in Canadian Service Sectors: An Initial Investigation of Inter-Sectoral Differences. The Service Industries Journal, 30(2): 225-246.

http:/dx.doi.org/10.1080/02642060802120174

Chandy, R., \& Tellis, G. J. 2000. Leader's Curse: Incumbency, Size \& Radical Innovation. Marketing Science Institute Report No. 00100. Cambridge, MA: Marketing Science Institute.

den Hertog, P. 2000. Knowledge-Intensive Business Services as CoProducers of Innovation. International Journal of Innovation Management, 4(4): 491-528.

http://dx.doi.org/10.1142/S136391960000024X

Easingwood, C. J. 1986. New Product Development for Service Companies. Journal of Product Innovation Management, 3(4): 264175.

http://dx.doi.org/10.1111/1540-5885.340264

Edgett, S., \& Parkinson, S. 1994. The Development of New Financial Services: Identifying Determinants of Success and Failure. International Journal of Service Industry Management, 5(4): 24-38. http://dx.doi.org/10.1108/09564239410068689

Eisenhardt, K. M. 1989. Agency Theory: An Assessment and Review. Academy of Management Review, 14(1): 57-74. http://dx.doi.org/10.5465/AMR.1989.4279003

\section{About the Author}

Shiv S. Tripathi is an Assistant Professor in the area of Strategic Management at the Management Development Institute in Gurgaon, India. He holds a PhD degree from Vinod Gupta School of Management at the Indian Institute of Technology Kharagpur. He has published papers in the area of product and service innovations, growth strategies, and innovations in large organizations. He has presented papers at national and international conferences organized by the Indian Institutes of Management, Indian School of Business, and Strategic Management Society, USA. His current research interests include service innovations, open innovations, ambidexterity, and innovation in large organizations.
Gallouj, F. 2002. Innovation in the Service Economy: The New Wealth of Nations. Cheltenham, UK: Edward Elgar.

Jensen, M. C., \& Meckling, W. H. 1976. Theory of the Firm: Managerial Behavior, Agency Costs, and Ownership Structure. Journal of Financial Economics, 3(4): 305-360. http://dx.doi.org/10.2139/ssrn.94043

de Jong, J. P. J., Bruins, A., Dolfsma, W., \& Meijaard, J. 2003. Innovation in Service Firms Explored: What, How and Why? The Netherlands: EIM Business and Policy Research.

McGrath, R. G. 2013. The End of Competitive Advantage. Boston: Harvard Business School Press.

OECD. 2005. OECD SME and Entrepreneurship Outlook. Paris: Organisation for Economic Co-operation and Development (OECD).

Pavitt, K. 1984. Sectoral Patterns of Technical Change: Towards a Taxonomy and a Theory. Research Policy, 13(6): 343-373. http://dx.doi.org/10.1016/0048-7333(84)90018-0

Si, S., \& Wei, F. 2012. Transformational and Transactional Leaderships, Empowerment Climate and Innovation Performance: A Multilevel Analysis in the Chinese Context. European Journal of Work and Organizational Psychology, 21(2): 299-320. http://dx.doi.org/10.1080/1359432X.2011.570445

Strauss, A., \& Corbin J. 1998. Basics of Qualitative Research: Techniques and Procedures for Developing Grounded Theory (2nd Ed.). Thousand Oaks, CA: Sage Publications.

Tether, B. S., \& Hipp, C. 2002. Knowledge Intensive, Technical and Other Services: Patterns of Competitiveness and Innovation Compared. Technology Analysis and Strategic Management, 14(2): 163-182.

http://dx.doi.org/10.1080/09537320220133848

Thamhain, H. J. 2003. Managing Innovative R\&D teams. R\&D Management, 33(3): 297-311. http://dx.doi.org/10.1111/1467-9310.00299 


\section{The Role of Managers as Agents in Successful Service Innovations}

\section{Shiv S. Tripathi}

Tidd, J., \& Bessant, J. 2009. Managing Innovation: Integrating Technological, Market and Organizational Change (4th Ed.). West Sussex, England: John Wiley \& Sons.

Tripathi, S. S., Guin, K. K., \& De, S. K. 2013. Product and Service Innovations in Large Organizations Operating in India: A Systems Approach. IUP Journal of Business Strategy, 10(3): 32-52.

Van de Ven, A. H. 1986. Central Problems in the Management of Innovation. Management Science, 32(5): 590-607.

http://dx.doi.org/10.1287/mnsc.32.5.590

Wren, D. A., \& Greenwood, R. G. 1998. Management Innovators: The People and Ideas That Have Shaped the Modern Business. New York: Oxford University Press.

Citation: Tripathi, S. S. 2014. The Role of Managers as

Agents in Successful Service Innovations. Technology

(cc) BY

Innovation Management Review, 4(8): 18-26.

http://timreview.ca/article/819

Keywords: service innovation, agents, managers, India, global organizations, entrepreneurship, intrapreneurship 